\title{
Transition in Deformation Mechanism of AZ31 Magnesium Alloy during High-Temperature Tensile Deformation
}

\author{
Masafumi Noda, ${ }^{1}$ Hisashi Mori, ${ }^{2}$ and Kunio Funami ${ }^{1}$ \\ ${ }^{1}$ Department of Mechanical Science and Engineering, Chiba Institute of Technology, 2-17-1, Tsudanuma, Narashino, \\ Chiba 275-0016, Japan \\ ${ }^{2}$ Materials Technology Division, Railway Technical Research Institute, 2-8-38, Hikari-machi, Kokubunji, Tokyo 185-8540, Japan \\ Correspondence should be addressed to Hisashi Mori, forest@rtri.or.jp
}

Received 24 December 2010; Revised 20 April 2011; Accepted 6 May 2011

Academic Editor: Chong Soo Lee

Copyright (C) 2011 Masafumi Noda et al. This is an open access article distributed under the Creative Commons Attribution License, which permits unrestricted use, distribution, and reproduction in any medium, provided the original work is properly cited.

Magnesium alloys can be used for reducing the weight of various structural products, because of their high specific strength. They have attracted considerable attention as materials with a reduced environmental load, since they help to save both resources and energy. In order to use $\mathrm{Mg}$ alloys for manufacturing vehicles, it is important to investigate the deformation mechanism and transition point for optimizing the material and vehicle design. In this study, we investigated the transition of the deformation mechanism during the high-temperature uniaxial tensile deformation of the AZ31 Mg alloy. At a test temperature of $523 \mathrm{~K}$ and an initial strain rate of $3 \times 10^{-3} \mathrm{~s}^{-1}$, the AZ31 Mg alloy (mean grain size: $\sim 5 \mu \mathrm{m}$ ) exhibited stable deformation behavior and the deformation mechanism changed to one dominated by grain boundary sliding.

\section{Introduction}

Recently, there has been a strong demand for measures that can be adopted to improve the energy efficiency of vehicles and to reduce $\mathrm{CO}_{2}$ emission. One such measure involves further reducing the weight of members or devices in vehicles [1-3]. Possible measures for weight reduction include reducing the number of vehicle parts, decreasing the member thickness, and using light materials. Another approach is to use $\mathrm{Mg}$ alloys, which are the lightest and the most promising metallic materials [4-6]. Thus, Mg alloys have been widely used in thixomolding and casting products $[7,8]$. To increase the utility of these alloys, attempts to increase their strength and formability have been made [9-12]. Mg alloys have been used in vehicles, and they have recently been used as secondary strength members in cell phones, electronic devices, and so forth $[13,14]$. Increasing the use of $\mathrm{Mg}$ alloys in the vehicle members of transport devices involves many challenges, including optimizing the plastic working and strengthening the alloys to allow the fabrication of members with various shapes.
Cold working is known to be a difficult process for conducting the plastic working of $\mathrm{Mg}$ alloys since the deformability of the alloys is extremely small at room temperature, because of the hexagonal close-packed structure of $\mathrm{Mg}$ alloys [15]. However, $\mathrm{Mg}$ alloys with a slip system other than the basal slip system can become more active; this results in a lower deformation resistance and a considerable increase in expansion when the deformation temperature increases. Therefore, considering the product precision and formability, plastic working of $\mathrm{Mg}$ alloy members is conducted mostly at high temperatures [16]. There are many reports on the strength, elongation, and superplasticity of $\mathrm{Mg}$ alloys [17-19]. However, to develop plastic working technology for Mg alloys, it is important to study the hightemperature deformation behavior of $\mathrm{Mg}$ alloys and their drawability and extrusion properties. The majority of studies on $\mathrm{Mg}$ alloys such as the Mg-Zn-Y $[20,21]$ and Mg-ZnGd $[22,23]$ alloys have neither addressed the development of technology for controlling the working nor included a detailed analysis of the deformation behavior. Furthermore, few researchers have reported on the transition points 
where the high-temperature deformation behavior of the AZ31 Mg alloy changes, although superplastic deformation has been investigated [24-27]. Therefore, in this study, we examined the transition points of the deformation mechanism observed under high-temperature deformation by conducting high-temperature uniaxial tensile tests on rolled AZ31 material and by evaluating the stability of the deformation mechanism during high-temperature deformation. The objective is to develop a plastic working technology for the AZ31 Mg alloy.

\section{Experimental Procedure}

The tensile specimen was an extruded rod of the AZ31 $\mathrm{Mg}$ alloy (rod diameter: $70 \mathrm{~mm}$; rod length: $800 \mathrm{~mm}$ ). The chemical composition of the rod (in mass\%) was as follows: Al, 3.0\%; Zn, 0.89\%; Mn, 0.5\%; Cu, 0.0016\%; Si, 0.028\%; $\mathrm{Fe}, 0.002 \%$; and $\mathrm{Mg}$ constituted the rest of the mass. Figure 1 shows an optical micrograph of the extruded material. The grain size of the extruded material was $27 \mu \mathrm{m}$. We cut out the rolled material from the extruded rod material such that it had a thickness of $5 \mathrm{~mm}$, a length of $50 \mathrm{~mm}$, and a width of $50 \mathrm{~mm}$; the cutting was performed by machining. The rolled material was then homogenized by maintaining it at $573 \mathrm{~K}$ for $1.8 \mathrm{ks}$ in an electric furnace and cooling it in water. After homogenization, the rolled material was maintained for $0.36 \mathrm{ks}$ in an electric furnace heated to $493 \mathrm{~K}$ and subjected to multipass rolling (rolling temperature: $493 \mathrm{~K}$; rolling rim speed: $0.17 \mathrm{~m} / \mathrm{s}$ ). Rolling was conducted so that the thickness would be progressively reduced from 5.0 to $2.5,1.5$, and $1.0 \mathrm{~mm}$, and the material was reheated in an electric furnace for $0.18 \mathrm{ks}$ when each pass was completed. The material was cooled in water after the thickness decreased to $1.0 \mathrm{~mm}$. Longitudinal section observations showed that the rolled plate had an isometric grain diameter of approximately $5 \mu \mathrm{m}$. A tensile specimen with a gauge length, width, and thickness of 8,4 , and $1 \mathrm{~mm}$, respectively, was obtained from the rolled material. Here, the direction of material extrusion, direction of rolling, and tensile direction were parallel. For the hightemperature tensile test conducted in an Ar atmosphere, the range of test temperatures was set to 523 to $623 \mathrm{~K}$, the range of initial strain rates was set to $3 \times 10^{-1}$ to $3 \times 10^{-4} \mathrm{~s}^{-1}$, and the rate of temperature increase was set to $0.17 \mathrm{~K} \mathrm{~s}^{-1}$. The temperature was maintained for $0.9 \mathrm{ks}$ when the target temperature was reached. After deformation, the structure was observed by optical microscopy and by field-emission scanning electron microscopy (FE-SEM). Figure 2 shows an optical micrograph of the longitudinal section structure, the inverse pole figure (IPF) map, and the pole figure (PF) map of the hot-rolled plate obtained by electron backscatter diffraction (EBSD). The EBSD analysis was conducted using a measured view of $150 \mu \mathrm{m} \times 150 \mu \mathrm{m}$ in $0.3 \mu \mathrm{m}$ steps. Figure 2(c) shows that the rolled material had a basal texture with a maximum intensity of 6.3 at $80 \%$ rolling reduction. The basal texture is considered to have developed because the number of passes was three and rolling was conducted at $493 \mathrm{~K}$ with reheating within a short period. The intensity of the basal texture and that of the sheet rolled using a single

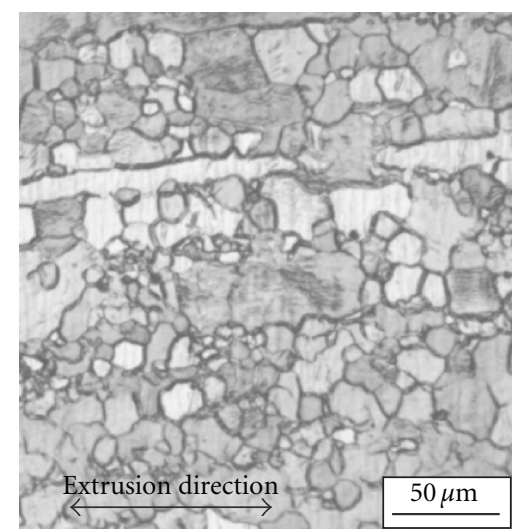

FIGURE 1: Optical micrograph of the as-extruded material.

roller when the AZ31 $\mathrm{Mg}$ alloy was subjected to working from 473 to $673 \mathrm{~K}$ until the rolling reduction reached $85.7 \%$ were found to be 7 and 5, respectively, although the grain is isometric [28].

\section{Results}

3.1. Mechanical Properties of High-Temperature Tensile Deformation. To study the effects of test temperatures and strain rate on tensile deformation, the nominal-stress-nominalstrain curve at test temperatures of 523,573 , and $623 \mathrm{~K}$ for initial strain rates of $3 \times 10^{-1} \mathrm{~s}^{-1}$ to $3 \times 10^{-4} \mathrm{~s}^{-1}$ are shown in Figure 3. The stress-strain behavior shows an increase in stress with concurrent work hardening during the initial stages of tensile deformation; the stress then reached a maximum, after which the tensile specimen broke and the stress decreased because of work hardening [29].

At the high strain rates in the range we considered, the tensile specimen broke suddenly after it showed the maximum stress. However, the level of work hardening as well as the maximum stress decreased as the initial strain rate decreased and the test temperature increased; a stationary deformation area and massive extension were observed under low stress. These behaviors are consistent with the high-temperature deformation and superplastic behavior of AZ-type Mg alloys [30, 31], Mg-RE (rare-earth) alloys [32, 33], and Al-Mg alloys [34].

\subsection{Effects of Strain Rate and Temperature on Breaking Elon-} gation and Maximum Stress. Figure 4 shows the effects of test temperature and strain rate on breaking elongation. The breaking elongation tended to increase as the initial strain rate decreased and the test temperature increased. At the high initial strain rate of $3 \times 10^{-1} \mathrm{~s}^{-1}$, the breaking elongation was nearly $100 \%$, regardless of the test temperature.

Figure 5 shows the effect of the test temperature and strain rate on deformation stress. Since the rigidity modulus is affected by the temperature, the deformation stress shown is normalized with the rigidity modulus at the maximum stress $[35,36]$. The rigidity modulus was calculated on the 


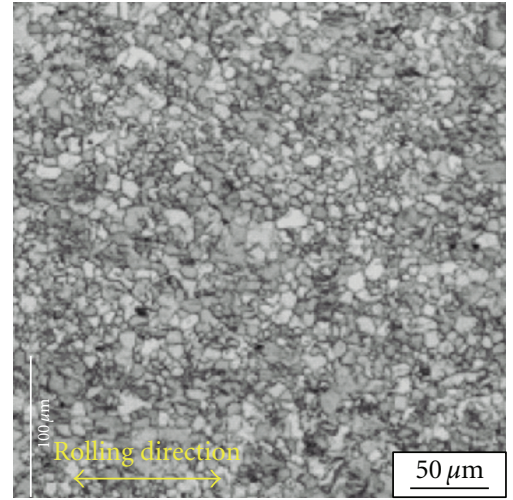

(a)
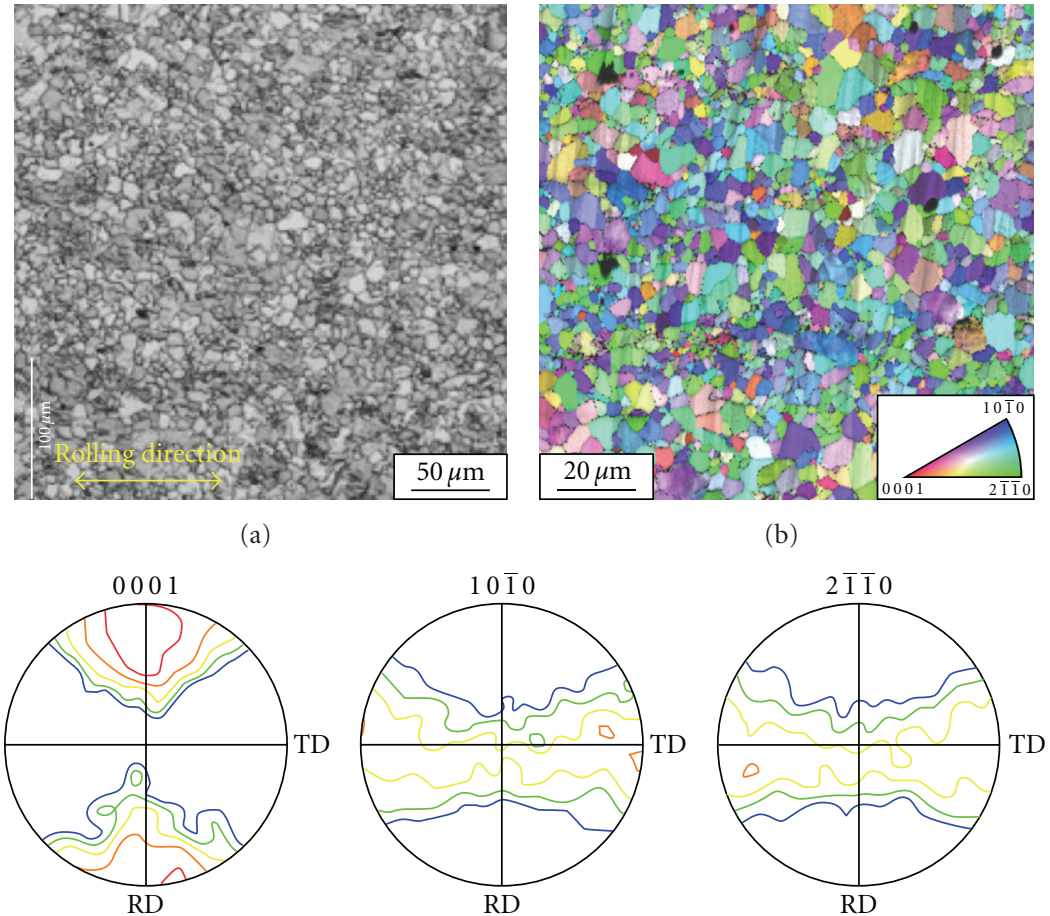

(b)

Max 6.3
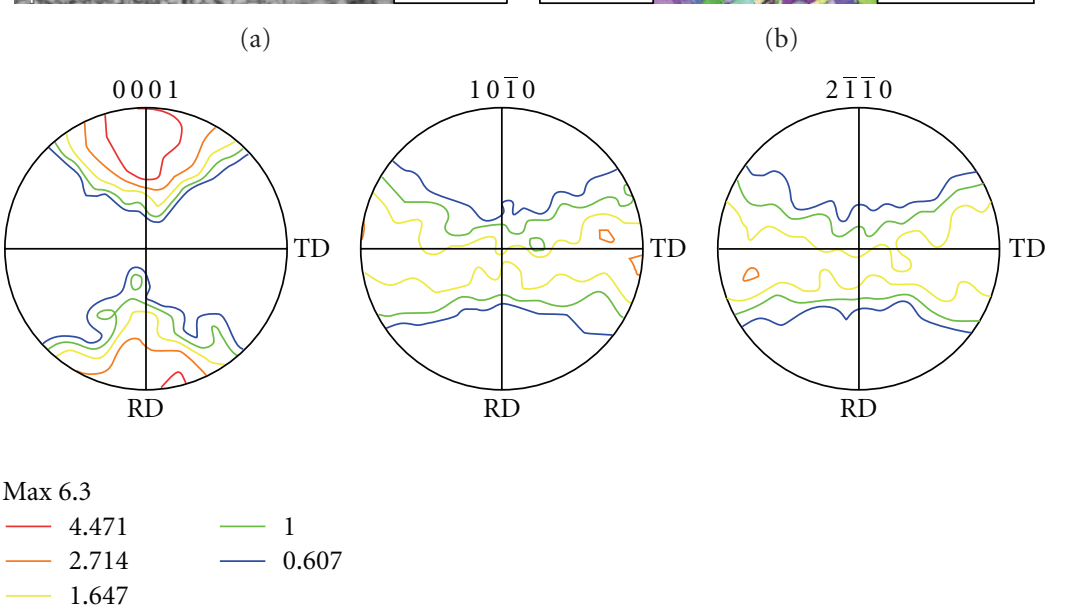

.

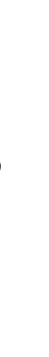




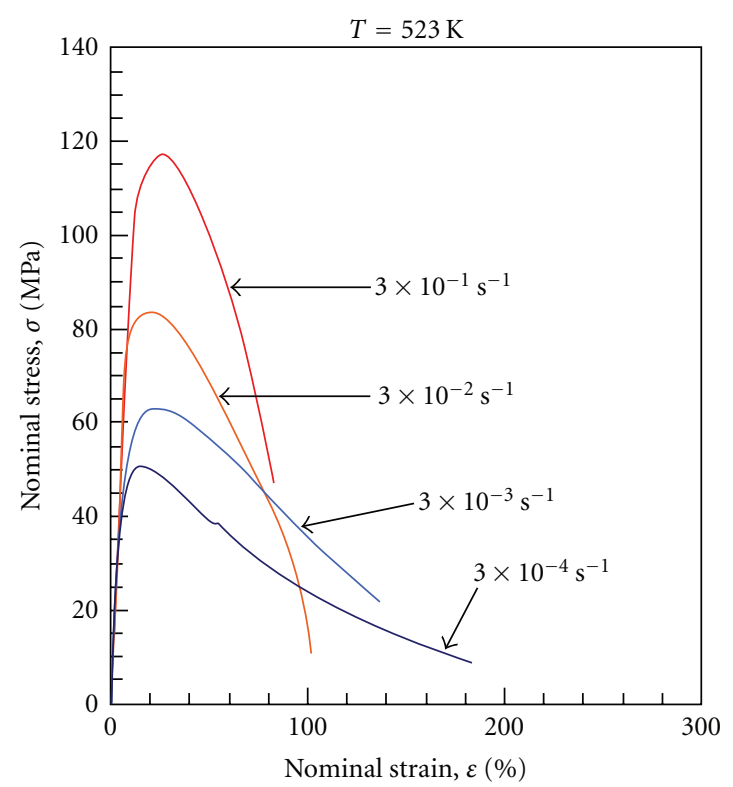

(a)

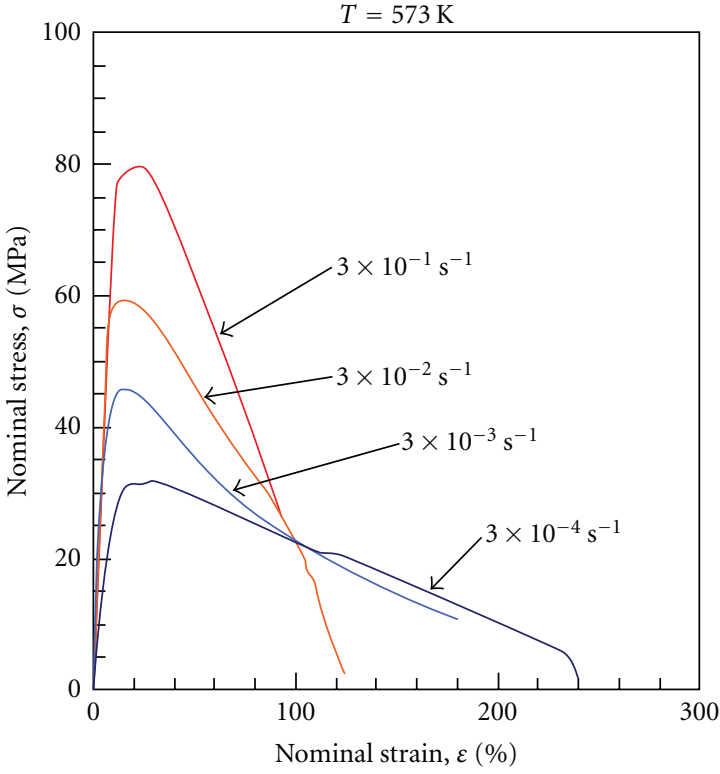

(b)

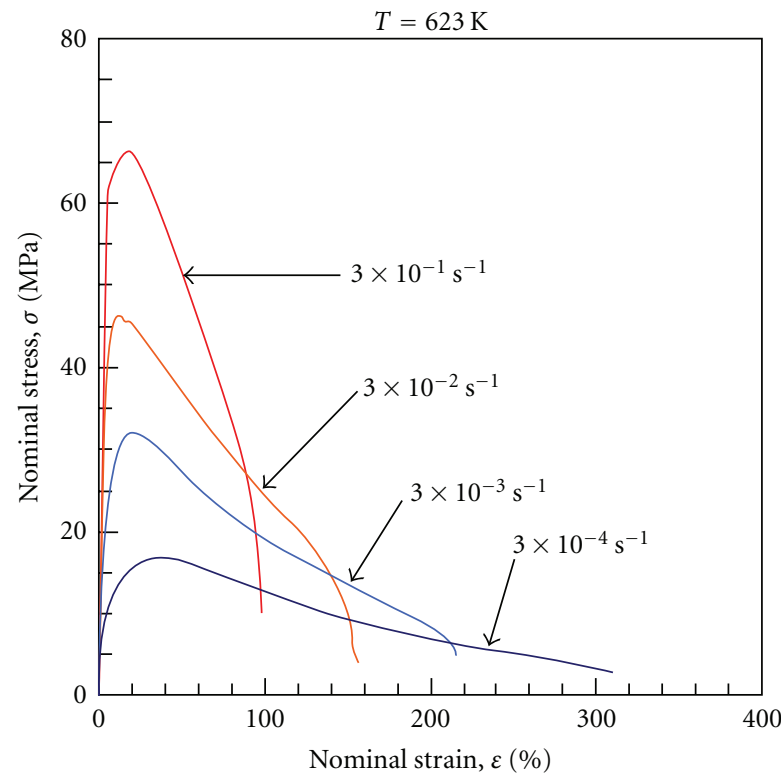

(c)

FIGURE 3: Nominal-stress-nominal-strain curves for tensile deformation at $523 \mathrm{~K}$ (a), $573 \mathrm{~K}$ (b), and $623 \mathrm{~K}$ (c) at an initial strain rate of $3 \times 10^{-1}$ to $10^{-4} \mathrm{~s}^{-1}$.

value for this curve is 0.2 and 0.3 for high and low strain rates, respectively.

3.4. Observation of Plate Surface Structure after High-Temperature Tensile Deformation. Figure 8 shows the deformed surface structure for the case in which the same degree of deformation was applied at each strain rate at $573 \mathrm{~K}$ and $623 \mathrm{~K}$. The surface structure was observed by optical microscopy. On the basis of the results shown in Figures 5-7, we selected $573 \mathrm{~K}$ and $623 \mathrm{~K}$ as the test temperatures and $3.0 \times 10^{-2}$ to $3.0 \times 10^{-4} \mathrm{~s}^{-1}$ as the range of initial strain rates, which was believed to include the point at which the deformation transition occurred. To compare the structural change before breaking, we varied the degree of deformation according to the nominal stress-strain curve shown in Figure 3. Figure 8 shows that isometric cavities were formed as the strain rate decreased and the test temperature increased, while cavities that elongated in the tensile direction were formed at high strain rates. On the basis of the SEM structure (Figure 10) described later, the cavities were considered to grow and merge without elongation in the tensile direction because of active occurrence of grain boundary sliding (GBS) under high-temperature and low-strain-rate conditions. Since the structures observed by optical microscopy at $573 \mathrm{~K}$ and 


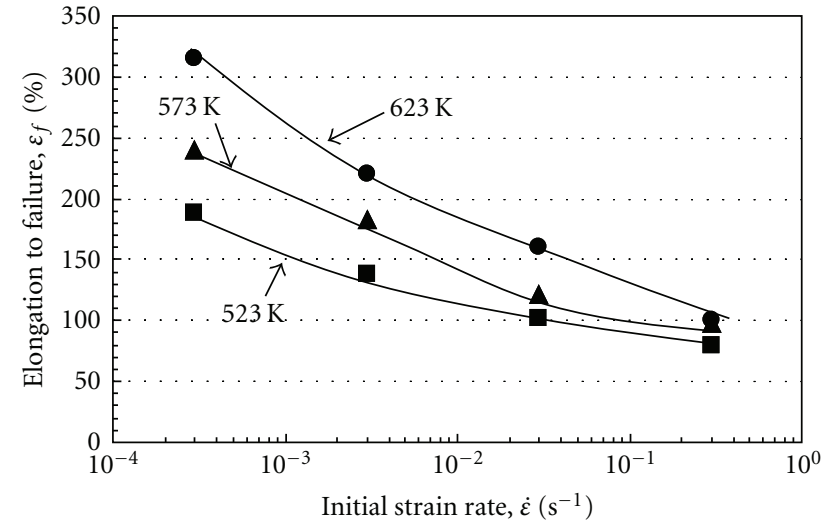

- $523 \mathrm{~K}$

- $573 \mathrm{~K}$

- $623 \mathrm{~K}$

FIGURE 4: Relationship between elongation and initial strain rate of the AZ31 Mg rolled sheet. The test temperature is indicated in the figure.

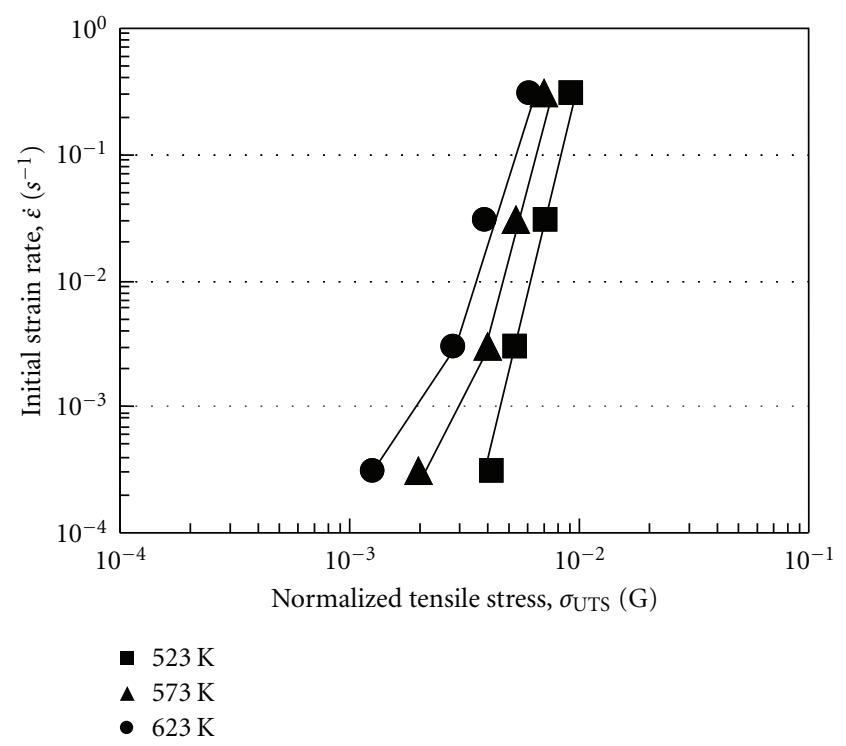

FIGURE 5: Relationship between the initial strain rate and tensile stress normalized by the shear modulus, for each test temperature.

$623 \mathrm{~K}$ were similar, we calculated the area fraction of cavities relative to the degree of deformation on the basis of these structures after causing deformation at $573 \mathrm{~K}$ and $623 \mathrm{~K}$ and initial strain rates of $3.0 \times 10^{-3} \mathrm{~s}^{-1}$ and $3.0 \times 10^{-4} \mathrm{~s}^{-1}$ (Figure 9). The area fraction of cavities relative to the degree of deformation increased as the test temperature increased and the strain rate decreased. At $573 \mathrm{~K}$, the area fraction of cavities was proportional to the degree of deformation, while at $623 \mathrm{~K}$, the relationship was proportional only until the degree of deformation reached $140 \%$ and the gradient of the area fraction of cavities varied with further deformation. To measure the area fraction of cavities while avoiding the effects of constriction, and so forth, which occur under a large deformation, we obtained measurements at a point

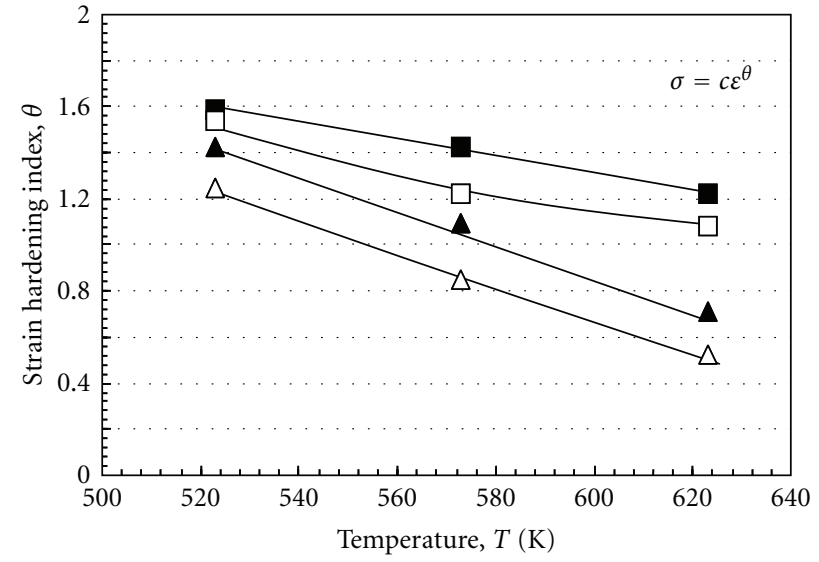

$$
\begin{array}{ll}
\text { ㄹ } \dot{\varepsilon}=3 \times 10^{-1} \mathrm{~s} & \Delta \dot{\varepsilon}=3 \times 10^{-3} \mathrm{~s} \\
\square \dot{\varepsilon}=3 \times 10^{-2} \mathrm{~s} & \Delta \dot{\varepsilon}=3 \times 10^{-4} \mathrm{~s}
\end{array}
$$

FIGURE 6: Relationship between the strain hardening ratio and test temperature.

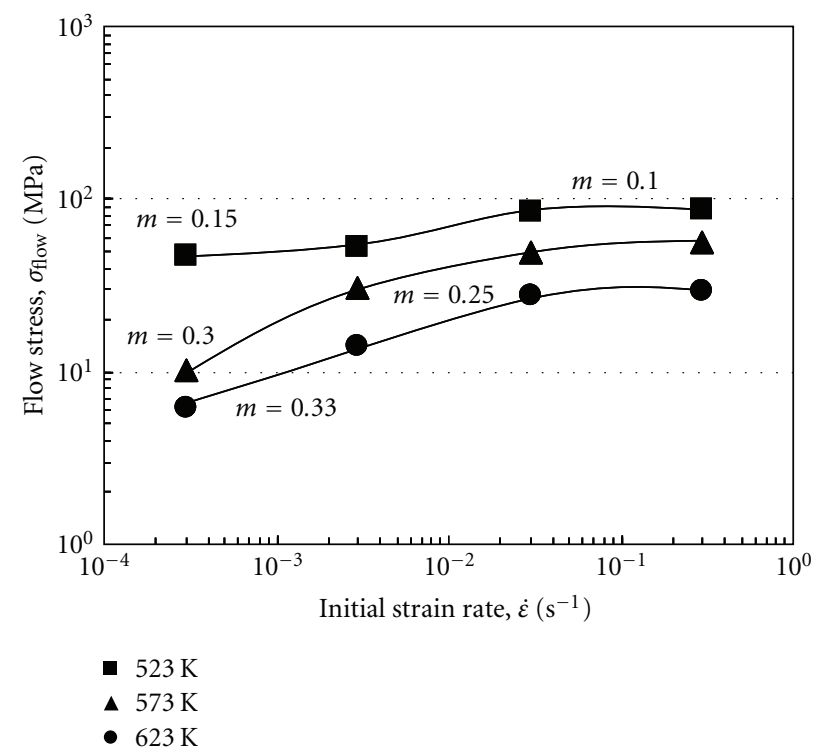

Figure 7: Relationship between the initial strain rate and plastic flow stress. The $m$ value is indicated in the figure.

$500 \mu \mathrm{m}$ from the center of the parallel section. Figure 10 shows the SEM structures of the plate surface of the tensile specimen subjected to various degrees of deformation at $573 \mathrm{~K}$ and $673 \mathrm{~K}$ and an initial strain rate of $3.0 \times 10^{-3} \mathrm{~s}^{-1}$. At $573 \mathrm{~K}$, GBS and transgranular sliding occurred and generated minute cavities on grain boundaries, although little unevenness was caused by GBS at 20\% deformation. At $40 \%$ deformation, GBS was clearly dominant, and the surface of the tensile specimen was uneven. When the degree of deformation was $80 \%$ and higher, cavities were clearly observed and GBS occurred; further, a fiber-like structure $[38,39]$ was formed on the grain boundary, along with the growth of cavities. However, grains were not elongated in the tensile direction. At $673 \mathrm{~K}$, unevenness 


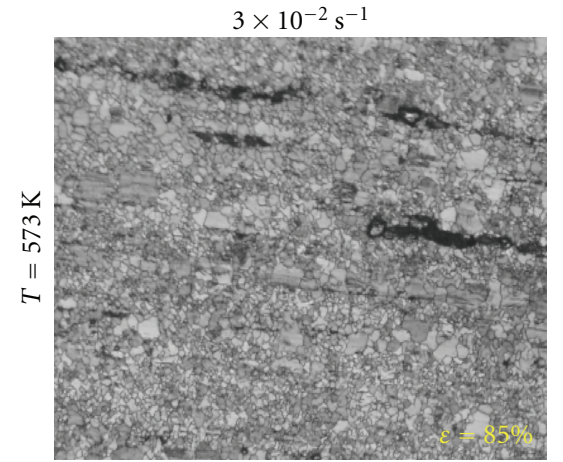

(a)

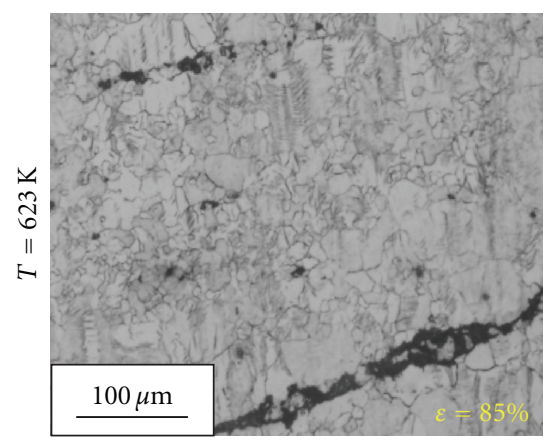

(d)

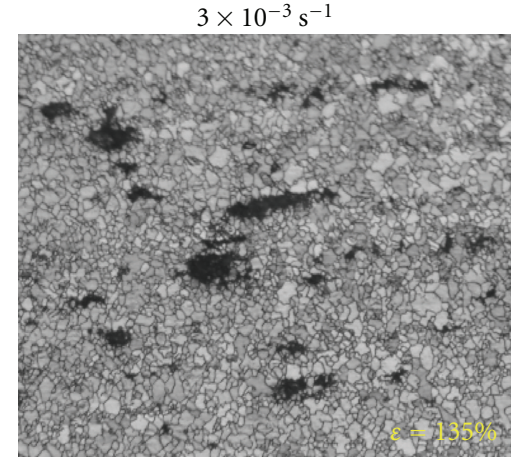

(b)

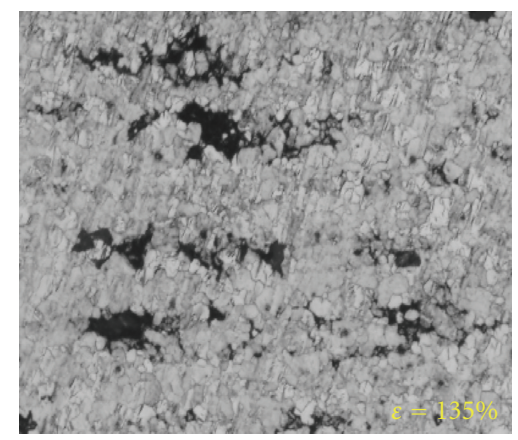

(e)

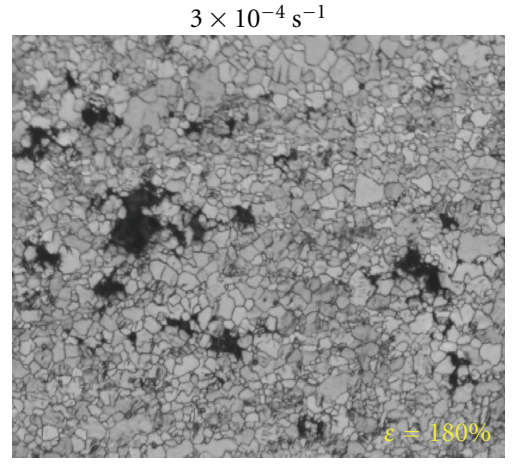

(c)

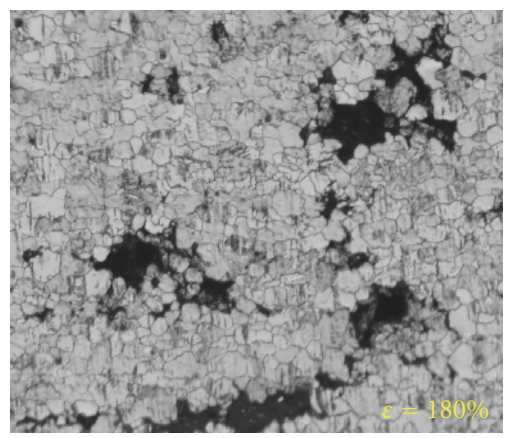

(f)

FIGURE 8: Optical micrographs of the as-rolled specimens deformed during tensile tests at $573 \mathrm{~K}$ (a)-(c) and $623 \mathrm{~K}$ (d)-(f), for $\varepsilon=85 \%$ (a, d), $\varepsilon=135 \%(b, e)$, and $\varepsilon=180 \%(c, f)$.

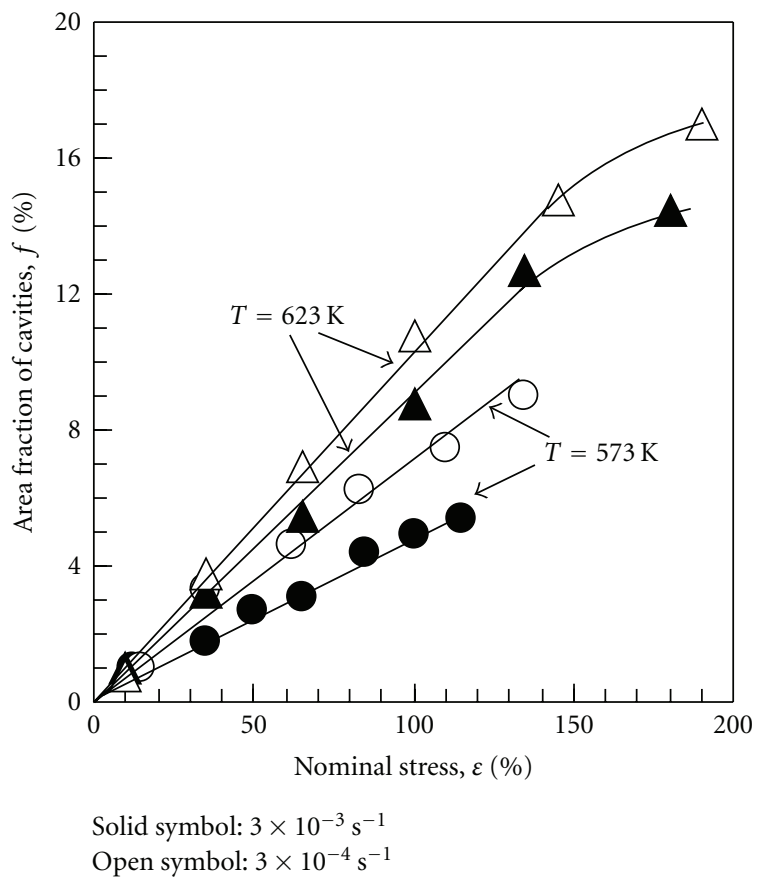

FIgURE 9: Relationship between the area fraction of cavities and nominal stress at $573 \mathrm{~K}$ and $623 \mathrm{~K}$ for each deformation ratio.

was clearly observed on the surface of the tensile specimen subjected to $20 \%$ deformation and a fiber-like structure and cavities formed on the grain boundary. It is surmised that the merging of cavities (Figure 10(g)) and transgranular sliding occurred as the degree of deformation was increased. Sliding deformation was more clearly observed at $623 \mathrm{~K}$ than at $573 \mathrm{~K}$. Transgranular sliding was reported even for deformation temperatures of $573 \mathrm{~K}$ and above when the strain rate was low and the degree of deformation of the extruded AZ61 material was 30\% [40]. The results of this study agree with this observation. The bending of the linear curve shown in Figure 5 at $573 \mathrm{~K}$ and $623 \mathrm{~K}$ and initial strain rates of $3.0 \times 10^{-3}$ to $3.0 \times 10^{-4} \mathrm{~s}^{-1}$, as well as the large $m$ value, are attributed to the fact that structural changes occurred mainly by GBS.

\section{Discussion}

4.1. Evaluation of the Stability of High-Temperature Deformation. On the basis of the experimental results, we found that the strength and breaking elongations of the AZ31 Mg alloy were dependent on the test temperature and strain rate at high temperatures; we also found that the mode of breaking changed from one involving constriction to one involving uniform elongation as the test temperature increased and the initial strain rate decreased. For stable and uniform deformation, the local deformation stress concurrent with work hardening should decrease and the constriction resistance ( $m$ value) should increase according to the local constriction deformation. However, the stability may vary depending on the constriction shape, even when the constriction is allowed to grow. To discuss the stability during deformation, 


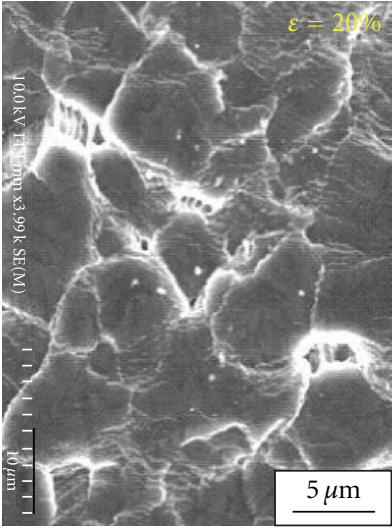

(a)

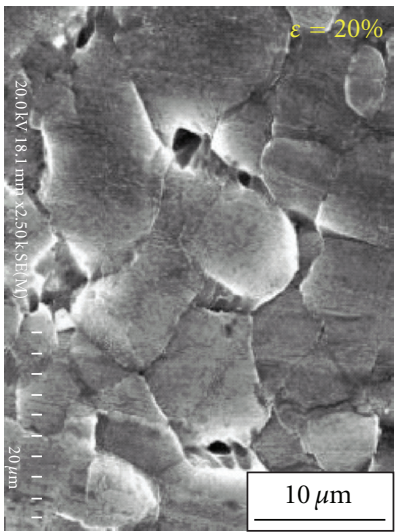

(e)

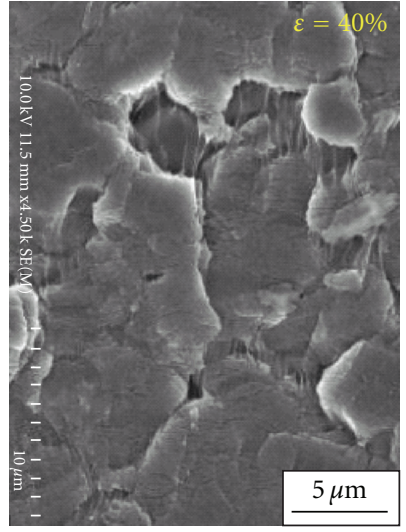

(b)

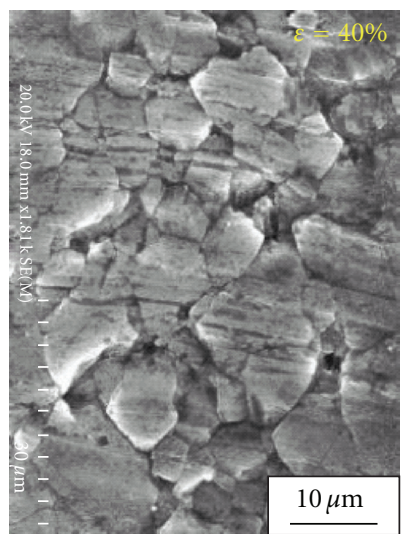

(f)

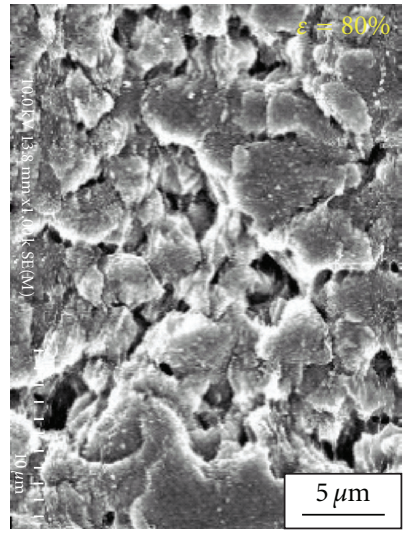

(c)

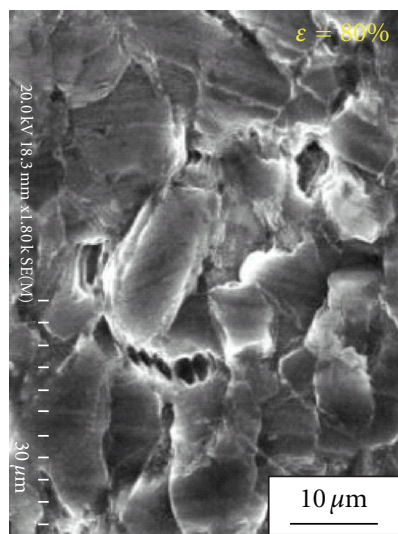

(g)

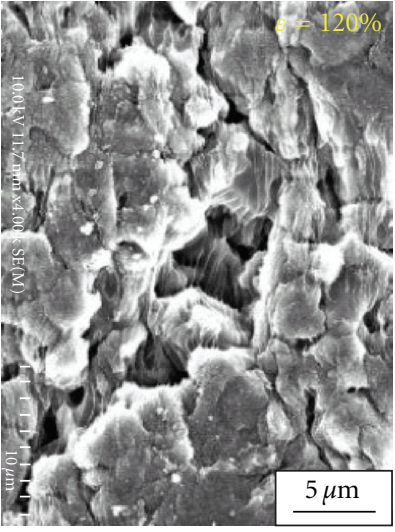

(d)

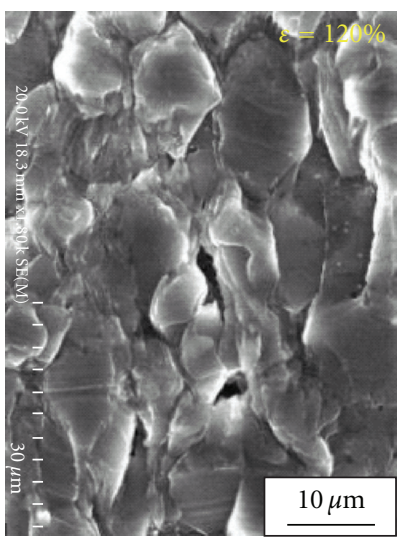

(h)

FIGURE 10: SEM micrographs of the as-rolled specimens deformed during tensile tests at $573 \mathrm{~K}$ (a)-(d) and $623 \mathrm{~K}$ (e)-(h) at an initial strain rate of $3 \times 10^{-3} \mathrm{~s}^{-1}$, for tensile deformation ratios of $20 \%(\mathrm{a}, \mathrm{e}), 40 \%(\mathrm{~b}, \mathrm{f}), 80 \%(\mathrm{c}, \mathrm{g})$, and $120 \%(\mathrm{~d}, \mathrm{~h})$. The tensile direction is along the vertical direction.

parameters that indicate the changes in the shape of the constriction are required. Sato et al. [41] discussed such parameters and considered the deformation stability by introducing $I$ in the following equation:

$$
I(\varepsilon)=\frac{(\gamma-1)}{m} .
$$

Here, $\gamma$ denotes the work hardening index and $m$ denotes the strain rate sensitivity. According to the analysis by Sato et al. [41], constriction growth can be evaluated as follows: depending on $I$ : constriction does not grow when $I>0$, it grows slowly when $-1<I<0$, and it grows gradually from the beginning of deformation until it breaks; when $-2<I$, the constriction grows sharply.

Therefore, we calculated $I(\varepsilon)$ by substituting for the work hardening index in (2), while setting $\varepsilon$ to $0.1,0.2$, and 0.3 on the basis of the nominal stress-strain curve shown in Figure 3; further, we obtained the $m$ value from Figure 7. The analytical results of the tensile test at $623 \mathrm{~K}$ are shown in Figure 11. $I(\varepsilon)$ decreases as the deformation increases, that is, as the work hardening decreases relative to the strain increment. Here, $I$ decreases to -2 or less for strain rates of $3 \times 10^{-1}$ to $10^{-2} \mathrm{~s}^{-1}$, while it is close to -2 at low strain rates of $3 \times 10^{-3}$ to $10^{-4} \mathrm{~s}^{-1}$. For a similar analysis, $I$ was close to -2 at $573 \mathrm{~K}\left(3 \times 10^{-4} \mathrm{~s}^{-1}\right)$ and -2 or less in all other cases. The results of this study show that to achieve stable deformation, the work hardening and constriction resistance must be balanced to cope with the large elongation; the results also show that the stability can be evaluated using $I(\varepsilon)$.

4.2. Transition of Deformation Mechanism. Figure 7 shows that the deformation mechanism for the test temperature of $573 \mathrm{~K}$ is represented by a gradual curve. The stress index under these conditions corresponded to the bending, and the test conditions $\left(523 \mathrm{~K}\right.$ and $\left.3 \times 10^{-3} \mathrm{~s}^{-1}\right)$ seemed to correspond to the point of transition of the deformation mechanisms. The high-temperature deformation map for pure Mg reported by Ashby and Verrall [42] indicates that the area that corresponds to the strength and temperature considered in this study seems to be the section where the deformation mechanism of the AZ31 Mg alloy shifts from plasticity to power-law creep. Although pure $\mathrm{Mg}$ and $\mathrm{Mg}$ alloys differ, a transition of the deformation mechanism is thought to occur for the AZ31 Mg alloy as well. Here, the structural observations reported by Noda et al. [43] indicate that the AZ31 Mg alloy is a fine-grain Al-Mg alloy but it 


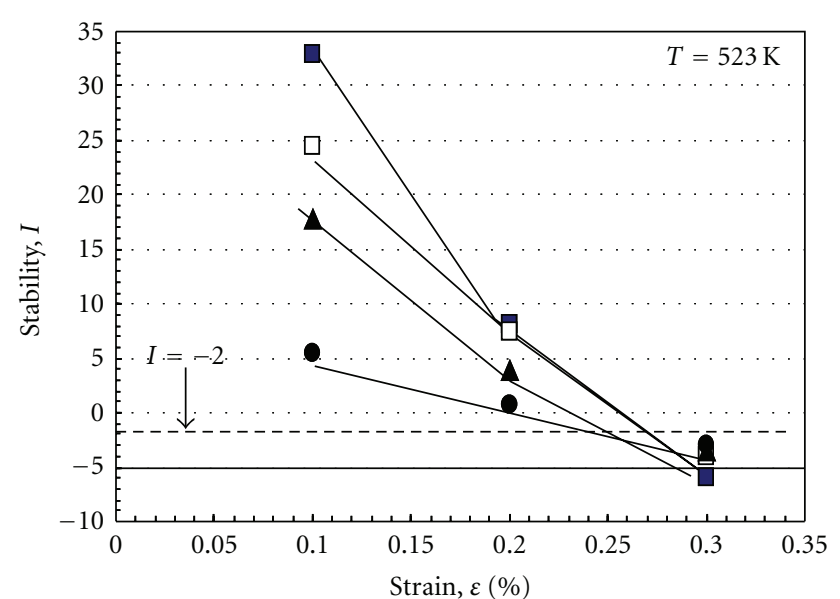

(a)

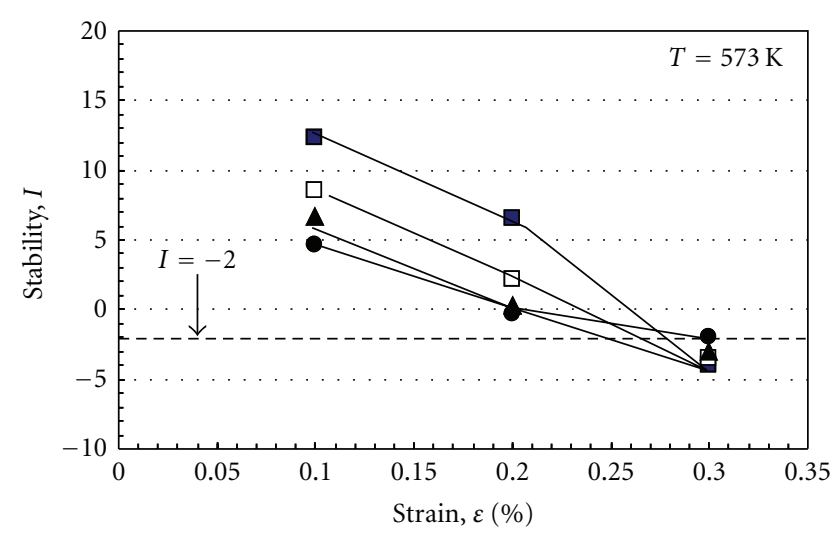

(b)

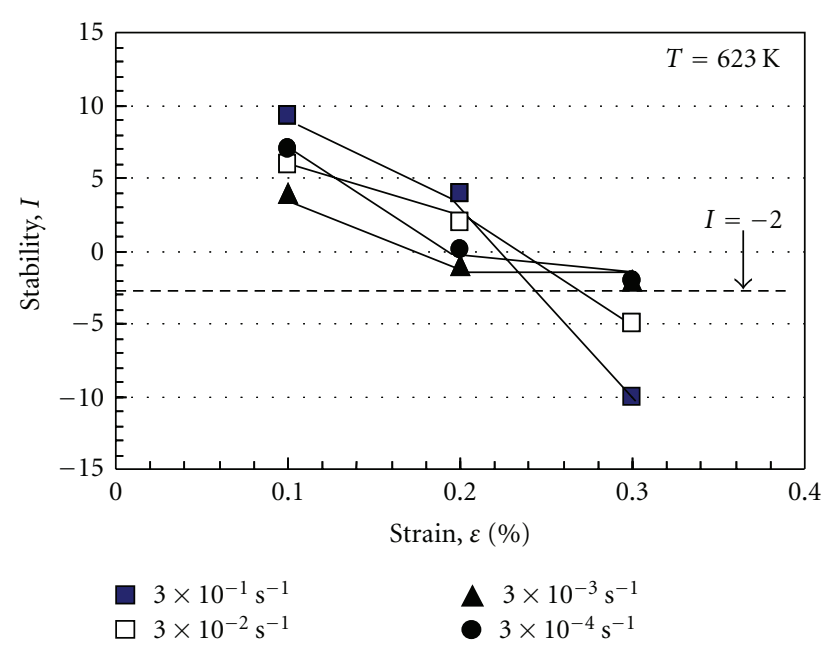

(c)

FIgURE 11: The dependence of the initial strain rate on neck stability (I), for several values of $I$ calculated using (2); (a) $523 \mathrm{~K}$, (b) $573 \mathrm{~K}$, and (c) $623 \mathrm{~K}$. changes with the superplastic deformation mechanism at a test temperature of $473 \mathrm{~K}$, owing to GBS and transgranular sliding. For initial grain sizes of $3 \mu \mathrm{m}$ or less, a large elongation of over $200 \%$ can occur in the low-temperature range via transgranular sliding as the main deformation mechanism [34].

On the basis of structural observation, we assumed that the deformed section is the cause of the transition of the deformation mechanism. On the basis of the structural observations shown in Figure 10, as well as Figures 57 and 11, we assume that the deformation mechanism changes at $573 \mathrm{~K}$ and $3 \times 10^{-3} \mathrm{~s}^{-1}$. To study the deformation structure under these conditions, we performed SEM observation of the deformation structure after $40 \%$ deformation (Figure 12). Since we observed the projections of grain boundaries, the formation of the fiber structure on the grain boundaries, as well as minute cavities among the fiber structures, we assumed that GBS with concurrent formation of minute cavities was the main deformation mechanism [38, 39]. Figure 12(b) shows the observed deformation structure; crease-like patterns (indicated by arrows) were observed within the grains and transgranular sliding also occurred. Substructures are formed inside the grains of the material when it is deformed at a high rate and a low temperature [44]. The experimental results presented so far suggest that GBS is the main mechanism under low strain rates that result in stable deformation. For the AZ31 Mg alloy used in this study (grain size: $\sim 5 \mu \mathrm{m}$ ), the change in the deformation mechanism at $523 \mathrm{~K}$ and $3 \times 10^{-3} \mathrm{~s}^{-1}$ is attributed to (1) the change in the stable deformation behavior, (2) the change in the deformation mechanism to one dominated by GBS, and (3) the influence of the stability of the plastic deformation concurrent with GBS on the transition.

\section{Conclusion}

We conducted high-temperature tensile tests and evaluated the high-temperature deformation behavior and deformation mechanism of the AZ31 Mg alloy, to obtain basic data for developing plastic working technology. We obtained the following results.

(1) For the AZ31 Mg alloy, the high-temperature behavior mainly depends on the strain rate and deformation temperature. A stationary deformation area was observed, and a large elongation was evident as the temperature increased and strain rate decreased.

(2) The strain rate affects the work hardening and constriction resistance during high-temperature deformation. The stability of high-temperature deformation was evaluated by using the stability parameters $I(\varepsilon)$ obtained from the work hardening and constriction resistance; $I$ was close to -2 for test conditions under which the large elongation occurred, and -2 or less under other test conditions. Therefore, $I$ is an effective parameter for evaluating stability.

(3) The AZ31 Mg alloy used in this study had a grain size of approximately $5 \mu \mathrm{m}$. It is assumed that the 


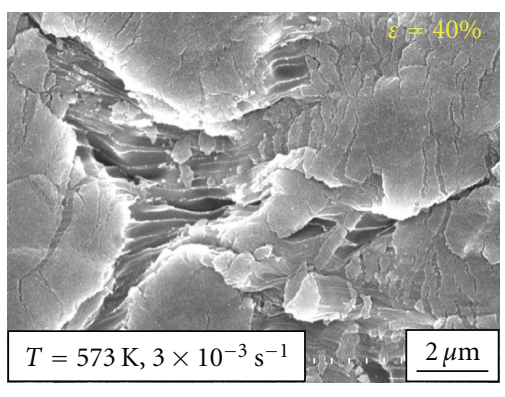

(a)

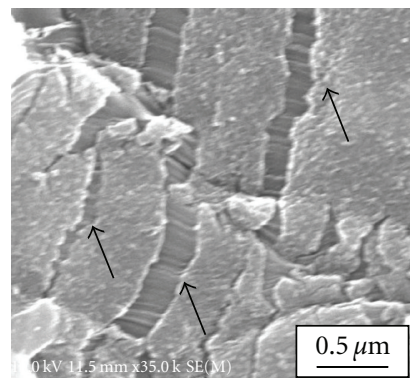

(b)

FIGURE 12: The slip morphology on the specimen surface after $40 \%$ tensile deformation at a strain rate of $3 \times 10^{-3} \mathrm{~s}^{-1}$ and a temperature of $573 \mathrm{~K}$.

deformation mechanism changes beyond the test temperature of $523 \mathrm{~K}$ and the initial strain rate of $3 \times 10^{-3} \mathrm{~s}^{-1}$ because of a change in the stable deformation behavior and transition in the deformation mechanism that is mainly dominated by GBS. It is also assumed that the transition is affected by the GBS concurrent with deformation.

\section{Acknowledgment}

This work was supported by the Advanced Machining Technology \& Development Association (AMTDA).

\section{References}

[1] A. Tharumarajah and P. Koltun, "Is there an environmental advantage of using magnesium components for lightweighting cars?" Journal of Cleaner Production, vol. 15, no. 1112, pp. 1007-1013, 2007.

[2] C. H. Caceres, "Economical and environmental factors in light alloys automotive applications," Metallurgical and Materials Transactions A, vol. 38, no. 7, pp. 1649-1662, 2007.

[3] J. Gediga and M. Betz, "Environmental benefits of new materials in automotive applications-LCE focusing on the recycling phase," Journal of Advanced Science, vol. 13, pp. 222-225, 2001.

[4] S. G. Pantelakis, N. D. Alexopoulos, and A. N. Chamos, "Mechanical performance evaluation of cast magnesium alloys for automotive and aeronautical applications," Journal of Engineering Materials and Technology, Transactions of the ASME, vol. 129, no. 3, pp. 422-430, 2007.

[5] C. R. Chakravorty, "Development of ultra light magnesiumlithium alloys," Bulletin of Materials Science, vol. 17, no. 6, pp. 733-745, 1994.

[6] H. Mori, M. Noda, and T. Tsujimura, "Feature view for application of advanced technology on metallic materials on technology for railway," Railway Research Review, vol. 62, pp. 26-29, 2005.

[7] B. L. Mordike and T. Ebert, "Magnesium propertiesapplications-potential," Materials Science and Engineering A, vol. 302, no. 1, pp. 37-45, 2001.

[8] F. Czerwinski, "Size evolution of the unmelted phase during injection molding of semisolid magnesium alloys," Scripta Materialia, vol. 48, no. 4, pp. 327-331, 2003.

[9] Y. Kawamura, K. Hayashi, A. Inoue, and T. Masumoto, "Rapidly solidified powder metallurgy MgZnY alloys with excellent tensile yield strength above $600 \mathrm{MPa}$," Materials Transactions, vol. 42, no. 7, pp. 1172-1176, 2001.

[10] Y. Chino, M. Kado, and M. Mabuchi, "Compressive deformation behavior at room temperature $-773 \mathrm{~K}$ in $\mathrm{Mg}-0.2$ mass\%(0.035at.\%)Ce alloy," Acta Materialia, vol. 56, no. 3, pp. 387-394, 2008.

[11] Y. Wang, S. B. Kang, and J. Cho, "Microstructural evolution of twin-roll cast Mg-3Al-0.5Mn-0.2Mm alloys during warm rolling and subsequent annealing," Journal of Materials Processing Technology, vol. 210, no. 10, pp. 1270-1275, 2010.

[12] C. Sanchez, G. Nussbaum, P. Azavant, and H. Octor, "Elevated temperature behaviour of rapidly solidified magnesium alloys containing rare earths," Materials Science and Engineering A, vol. 221, no. 1-2, pp. 48-57, 1996.

[13] S. Logan, "Magnesium technology 2007," in The Minerals, Metals and Materials Society, S. Randy et al., Ed., pp. 41-49, 2007.

[14] M. Noda, H. Mori, K. Funami, T. Tsujimura, and K. Higashi, "Screw processing by hot form rolling on magnesium alloy," Journal of the Japan Society for Technology of Plasticity, vol. 48, pp. 427-430, 2007.

[15] H. Yoshinaga and R. Horiuchi, "On the flow stress of $\alpha$ solid solution Mg-Li alloy single crystals," Transactions of the Japan Institute of Metals, vol. 4, pp. 134-141, 1963.

[16] A. Takara, Y. Nishikawa, H. Watanabe, H. Somekawa, T. Mukai, and K. Higashi, "New forming process of threedimensionally shaped magnesium parts utilizing high-strainrate superplasticity," Materials Transactions, vol. 45, no. 8, pp. 2531-2536, 2004.

[17] J. M. Boileau, P. A. Friedman, D. Q. Houston, and S. G. Luckey, "Superplastic response of continuously cast AZ31B magnesium sheet alloys," Journal of Materials Engineering and Performance, vol. 19, pp. 467-480, 2010.

[18] M. Liu, G. Yuan, Q. Wang, Y. Wei, W. Ding, and Y. Zhu, "Superplastic behavior and microstructural evolution in a commercial Mg-3Al-1Zn magnesium alloy," Materials Transactions, vol. 43, no. 10, pp. 2433-2436, 2002.

[19] R. Panicker, A. H. Chokshi, R. K. Mishra, R. Verma, and P. E. Krajewski, "Microstructural evolution and grain boundary sliding in a superplastic magnesium AZ31 alloy," Acta Materialia, vol. 57, no. 13, pp. 3683-3693, 2009.

[20] X. Zeng, Y. Zhang, C. Lu, W. Ding, Y. Wang, and Y. Zhu, "Precipitation behavior and mechanical properties of a MgZn-Y-Zr alloy processed by thermo-mechanical treatment," Journal of Alloys and Compounds, vol. 395, no. 1-2, pp. 213219, 2005. 
[21] D. H. Bae, Y. Kim, and I. J. Kim, "Thermally stable quasicrystalline phase in a superplastic Mg-Zn-Y-Zr alloy," Materials Letters, vol. 60, no. 17-18, pp. 2190-2193, 2006.

[22] G. Yuan, Y. Liu, W. Ding, and C. Lu, "Effects of extrusion on the microstructure and mechanical properties of Mg- $\mathrm{Zn}$ Gd alloy reinforced with quasicrystalline particles," Materials Science and Engineering A, vol. 474, no. 1-2, pp. 348-354, 2008.

[23] S. M. He, L. M. Peng, X. Q. Zeng, W. J. Ding, and Y. P. Zhu, "Comparison of the microstructure and mechanical properties of a ZK60 alloy with and without $1.3 \mathrm{wt} . \%$ gadolinium addition," Materials Science and Engineering A, vol. 433, no. 1-2, pp. 175-181, 2006.

[24] J. A. del Valle, F. Carreño, and O. A. Ruano, "On the threshold stress for superplasticity in Mg-Al-Zn alloys," Scripta Materialia, vol. 57, no. 9, pp. 829-832, 2007.

[25] F. K. Abu-Farha and M. K. Khraisheh, "Mechanical characteristics of superplastic deformation of AZ31Magnesium alloy," Journal of Materials Engineering and Performance, vol. 16, no. 2, pp. 192-199, 2007.

[26] H. Watanabe, A. Takara, H. Somekawa, T. Mukai, and K. Higashi, "Effect of texture on tensile properties at elevated temperatures in an AZ31 magnesium alloy," Scripta Materialia, vol. 52, no. 6, pp. 449-454, 2005.

[27] K. Kitazono, E. Sato, and K. Kuribayashi, "Internal stress superplasticity in polycrystalline AZ31 magnesium alloy," Scripta Materialia, vol. 44, no. 12, pp. 2695-2702, 2001.

[28] Y. Chino, M. Mabuchi, R. Kishihara et al., "Mechanical properties and press formability at room temperature of AZ31 $\mathrm{Mg}$ alloy processed by single roller drive rolling," Materials Transactions, vol. 43, no. 10, pp. 2554-2560, 2002.

[29] N. Srinivasan, Y. V. R. K. Prasad, and P. Rama Rao, "Hot deformation behaviour of $\mathrm{Mg}-3 \mathrm{Al}$ alloy-A study using processing map," Materials Science and Engineering A, vol. 476, no. 1-2, pp. 146-156, 2008.

[30] T. Mukai, H. Watanabe, and K. Higashi, "Application of superplasticity in commercial magnesium alloy for fabrication of structural components," Materials Science and Technology, vol. 16, no. 11-12, pp. 1314-1319, 2000.

[31] W. J. Kim, S. W. Chung, C. S. Chung, and D. Kum, "Superplasticity in thin magnesium alloy sheets and deformation mechanism maps for magnesium alloys at elevated temperatures," Acta Materialia, vol. 49, no. 16, pp. 3337-3345, 2001.

[32] X. Liu, R. Chen, and E. Han, "High temperature deformations of Mg-Y-Nd alloys fabricated by different routes," Materials Science and Engineering A, vol. 497, no. 1-2, pp. 326-332, 2008.

[33] X. Yang, Z. X. Ming, D. Y. Lai, and F. X. Hui, "Superplasticity of Mg-Gd-Y alloy in tensile test at elevated temperature," Transactions of Nonferrous Metals Society of China, vol. 17, pp. s372-s375, 2007.

[34] M. Noda, K. Funami, M. Hirohashi, and M. Kobayashi, "Effect of grain size and microstructure on appearance of low temperature superplasticity in Al-Mg alloy," Materials Science Forum, vol. 447-448, pp. 435-440, 2004.

[35] S. Goto, K. Mori, and H. Yosinaga, "Effect of particle shape on the high temperature yield strength of dispersion-hardened nickel base alloys," Journal of the Japan Institute of Metals, vol. 50, pp. 154-161, 1986.

[36] S. P. Bhat and C. Laird, "High temperature cyclic deformation of nickel," Fatigue of Engineering Materials and Structures, vol. 1, pp. 59-77, 1979.

[37] H. Y. Wu and F. Z. Lin, "Mechanical properties and strainhardening behavior of Mg alloy AZ31B-H24 thin sheet,"
Materials Science and Engineering A, vol. 527, no. 4-5, pp. 1194-1199, 2010.

[38] Q. Yang and A. K. Ghosh, "Formability of ultrafine-grain Mg Alloy AZ31B at warm temperatures," Metallurgical and Materials Transactions A, vol. 39, no. 11, pp. 2781-2796, 2008.

[39] M. G. Zelin, "On micro-superplasticity”, Acta Materialia, vol. 45, no. 9, pp. 3533-3542, 1997.

[40] Y. N. Wang and J. C. Hung, "Transaction of dominant diffusion process during superplastic deformation in AZ61 magnesium alloys," Metallurgical and Materials Transactions A, vol. 35, pp. 555-562, 2004.

[41] E. Sato, K. Kuribayashi, and R. Horiuchi, "Study on plastic instability in superplastic deformation through analysis of the neck shape change," Journal of the Japan Institute of Metals, vol. 52, no. 11, pp. 1051-1056, 1988.

[42] M. F. Ashby and R. A. Verrall, "Diffusion-accommodated flow and superplasticity," Acta Metallurgica, vol. 21, no. 2, pp. 149$163,1973$.

[43] M. Noda, M. Hirohashi, and K. Funami, "Low temperature superplasticity and its deformation mechanism in grain refinement of Al-Mg alloy by multi-axial alternative forging," Materials Transactions, vol. 44, no. 11, pp. 2288-2297, 2003.

[44] M. M. Myshlyaev, H. J. McQueen, A. Mwembela, and E. Konopleva, "Twinning, dynamic recovery and recrystallization in hot worked Mg-Al-Zn alloy," Materials Science and Engineering A, vol. 337, no. 1-2, pp. 121-133, 2002. 

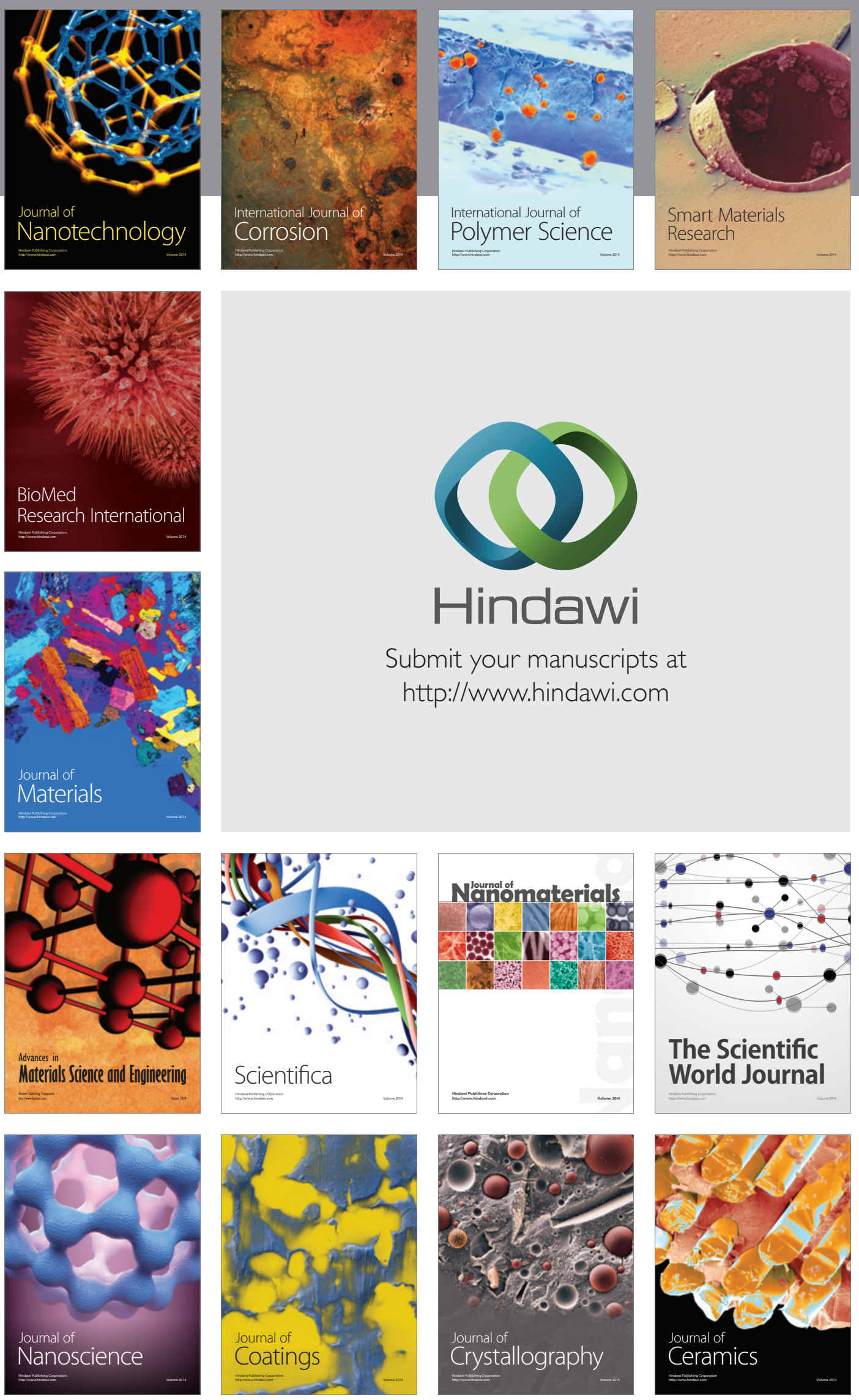

The Scientific World Journal

Submit your manuscripts at

http://www.hindawi.com

\section{World Journal}

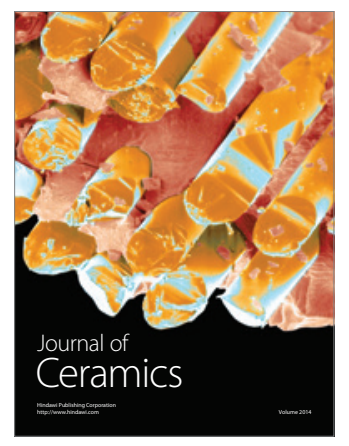

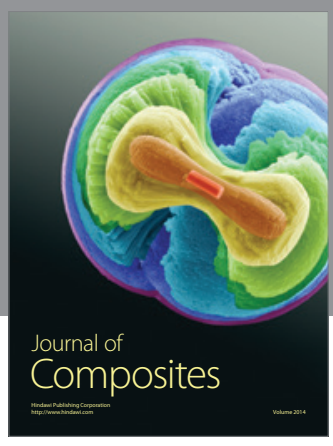
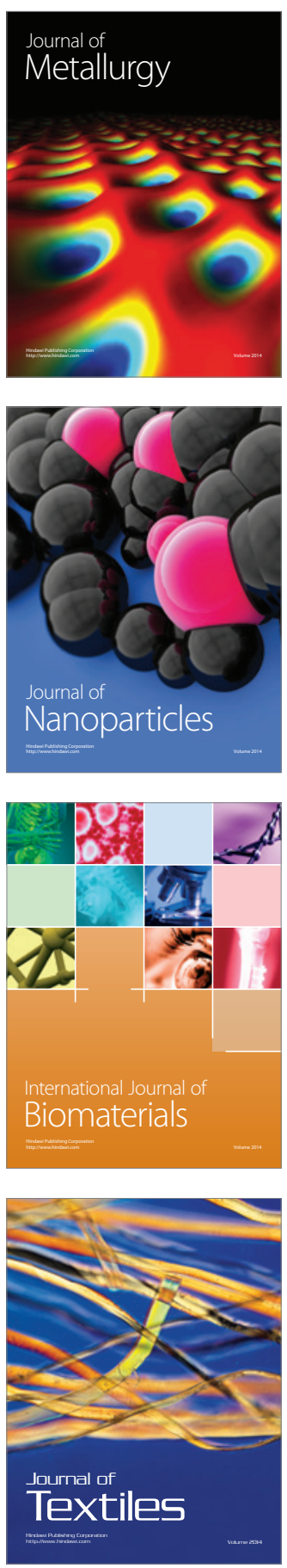